Научная статья

УДК 159.922.7(470+597)

DOI: $10.18101 / 2307-3330-2021-2-76-80$

\title{
ЛИЧНОСТНАЯ АВТОНОМИЯ ДЕТЕЙ РАННЕГО ВОЗРАСТА В РОССИЙСКОЙ И ВЬЕТНАМСКОЙ КУЛЬТУРЕ
}

\section{(C) Шинина Татьяна Валерьевна}

кандидат психологических наук, доцент, Московский государственный психолого-педагогический университет Россия, 127051, г. Москва, ул. Сретенка, 29 shininatv78@gmail.com

\section{(C) Морозова Инна Григорьевна \\ старший преподаватель, Российский государственный социальный университет Россия, 129226, г. Москва, ул. Вильгельма Пика, 4, стр. 1 inna.opinion@gmail.com}

Аннотация. В статье представлены материалы исследования, проведенного на выборке из диад родителей и детей раннего возраста. В исследовании приняли 50 диад из России (Москва, Екатеринбург) и Вьетнама (Нячанг) с детьми в возрасте от 10 до 12 месяцев $(\mathrm{M}=10,04 ; \mathrm{SD}=0,45)$, из которых 65\% были женского пола. Все респонденты из Вьетнама общались с ребенком на вьетнамском языке с дальнейшим транскрибированием текста и переводом на русский язык. Выборка уравновешена по социально-экономическому статусу семьи, возрасту, полу. Для оценки видеопротоколов использовали шкалу «Коммуникативных сигналов ребенка», для изучения социально-эмоционального развития ребенка - шкалу развития BayleyIII. Наблюдения были закодированы с помощью программного обеспечения «TheObserver XT-15». Математическая обработка данных - стат. пакет SPSS 26.0. Исследование показало, что развитие личностной автономии в российской и вьетнамской культуре связано с высоким уровнем исследовательской активности ребенка в процессе взаимодействия с родителем, дающим возможность ребенку самому проявить интерес к предметам и игрушкам, так уровень индикатора «Чувствительность к взрослому» имеет обратную корреляцию с индикатором «Инициатива к предмету» $(\mathrm{r}=-0,444$ прир $\leq 0,001$ по Спирмену) и «Предметная деятельность (r= -0,400 при $\mathrm{p} \leq 0,001$ по Спирмену).

Ключевые слова: метод наблюдения, ранний возраст, личностная автономия, видеоанализ, Observer-XT, схемы кодирования.

Благодарности. Работа выполнена при финансовой поддержке Российского фонда фундаментальных исследований (РФФИ) в рамках научного проекта № 19-51392001 «Кросс-культурные особенности взаимодействия значимого взрослого и ребенка в России и Вьетнаме».

\section{Для цитирования}

Шинина Т. В., Морозова И. Г. Личностная автономия детей раннего возраста в российской и вьетнамской культуре // Вестник Бурятского государственного университета. Образование. Личность. Общество. 2021. № 2. С. 76-80. 
T. В. Шинина, И. Г. Морозова. Личностная автономия детей раннего возраста в российской и вьетнамской культуре

Стремительные изменения в современном обществе, высокая интенсивность потоков информации, изменение коммуникации с переходом в онлайн-среду - все это оказывает значительное влияние на психическое развитие и формирование личности ребенка. Происходит разрыв между поколениями детей и родителей, снижается значимость фигуры взрослого и его роли в детско-родительском взаимодействии. Данная социальная ситуация развития требует научного осмысления и поиска новых путей оценки детско-родительского взаимодействия [4].

В настоящее время отмечается всплеск интереса зарубежных исследователей к изучению взаимодействия с помощью видеозаписей и шкал наблюдения. Современный обзор позволяет увидеть преимущества и недостатки методик оценки раннего детско-родительского взаимодействия [2]. Оценка детско-родительского взаимодействия NCAST [The Nursing Child Assessment Satellite Training] исследует способность подавать четкие и ясные сигналы взрослому и способность проявлять реакцию на действия или слова взрослого [6]. Шкала Manchester Assessmen to Caregiver-Infant [MACI] отмечает поведение ребенка по трем параметрам: детская внимательность по отношению к родителю, детский позитивный аффект, детская оживленность [5]. Оценка психологического взаимодействия родителя и ребенка в процессе кормления, структурированной и свободной игры [PCERA] The Parent Child Early Relational Assessment [6].

В процессе видеоисследования и проведения открытых профессиональных экспертиз была разработана система кодирования детской самостоятельности, позволяющая фиксировать индикатор в процессе анализа видеокейса, используя характеристики каждого индикатора [Шкала «Коммуникативных сигналов ребенка», Шинина, 2019]. Данную шкалу мы использовали для изучения формирования личностной автономии детей раннего возраста.

В своем исследовании мы поставили исследовательский вопрос: как происходит формирование и развитие личностной автономии в процессе детскородительского взаимодействия? Какие существуют кросс-культурные отличия развития в российской и вьетнамской культуре?

\section{Выборка}

$\mathrm{B}$ исследовании $(\mathrm{N}=50)$ приняли участие диады матерей и детей в возрасте от 10 до 12 месяцев ( $\mathrm{M}=10,04 ; \mathrm{SD}=0,45), 65 \%$ детей составляли девочки. Видеофиксация проходила в домашних условиях у испытуемых. Участники исследования не получали вознаграждение за участие. Были заключены этические соглашения с родителями. Анализ видеозаписей проводился двумя поведенческими аналитиками, прошедшими специальное обучение и достигшими при независимом анализе одних и тех же записей коэффициентов согласованности экспертных оценок индикаторов для ребенка $87 \%$-ного уровня совпадения результатов [5].

\section{Методы}

Использовалась методика изучения социально-эмоционального развития ребенка - Шкалы развития Bayley-III.

Методика оценки детско-родительского взаимодействия «Evaluation of ChildParent Interaction» [ECPI-2 ред.] и шкала «Коммуникативных сигналов ребенка» в процессе спонтанной игры со значимым взрослым. Процедура исследования включала в себя инструкцию для родителя: «Поиграйте с ребенком так, как вы играете дома». После чего 15 минут детско-родительского взаимодействия фиксировалось с 
использованием видеосъемки, позволяющей затем анализировать видеокейс, отмечая микродействия ребенка. При кодировке коммуникативной деятельности мы отмечали инициативные акты и ответные действия в адрес предмета и в адрес взрослого, выраженные коммуникативными сигналами как средствами общения. Для изучения коммуникативных сигналов «ребенок - предмет (П)» были использованы пять индикаторов оценки самостоятельной исследовательской активности ребенка с предметом.

Коммуникативные сигналы «ребенок - взрослый (В)» исследовались с помощью пяти индикаторов оценки сигналов ребенка, направленных на взаимодействие со взрослым. Каждый индикатор имеет положительное и отрицательное значение, что соответствует содержательным характеристикам $[1-4,11]$. Целостную картину поведения ребенка при взаимодействии с родителем мы смогли получить благодаря программному обеспечению «The Observer XT-15», позволяющему фиксировать частоту и длительность проявления каждого индикатора, констатировать средний и общий показатели длительности, а также количественные характеристики каждого индикатора. Протокол оценки индикаторов коммуникативных сигналов ребенка, включает в себя: а) составление схемы кодирования; б) статистический анализ; в) рейтинговый анализ достоверности, проводимый между несколькими наблюдателями в одном проекте; г) ввод данных.

Обработка полученных результатов проводилась в программе IBM SPSS Statistics 26.0. Были использованы методы математической обработки эмпирических данных: ковариационный, корреляционный, дисперсионный и факторный.

\section{Обсуждение}

Под личностной автономией понимается проявления в поведении, сознании, чувствах собственных личностных решений, а не социально ориентированных и одобряемых из вне. Личностная автономия рассматривается как интериоризованная форма внешней регуляции, ставшей саморегуляцией. Проявление личностной автономии служит показателем личностного здоровья и психической устойчивости, индикатором позитивной направленности личности $[7,8,10]$.

Основы личностной автономии формируются в раннем возрасте. Для того чтобы в ребенке сформировать личностную автономию как зрелую форму саморегуляции, необходимо осмыслить и проанализировать воспитательные стратегии значимых взрослых, применяемые с самого раннего возраста. Ребенку важно развиваться в условиях, которые поддерживают его самостоятельность, инициативность, исследовательскую активность.

\section{Результаты}

Результаты исследования показали, что личностная автономия ребенка связана с высоким уровнем интегрированности, открытостью опыту, когда ребенок способен открыто выражать свои эмоциональные переживания, включая отрицательные. Ребенок является автором собственных действий, действует в согласии с собственным внутренним состоянием. Инициатива ребенка связана с его активной субъектностью, свободой выбора действий, возможностью представления своих способов действий с предметом значимому взрослому. Личностная автономия задается двумя противоположными сценариями поведения ребенка.

Исследование показало, что развитие личностной автономии в российской и вьетнамской культуре связано с высоким уровнем исследовательской активности 
T. В. Шинина, И. Г. Морозова. Личностная автономия детей раннего возраста в российской и вьетнамской культуре

ребенка в процессе взаимодействия с родителем, дающим возможность ребенку самому проявить интерес к предметам и игрушкам, так уровень индикатора «Чувствительность к взрослому» имеет обратную корреляцию с индикатором «Инициатива к предмету» ( $\mathrm{r}=-0,444$ прир $\leq 0,001$ по Спирмену) и «Предметная деятельность $(\mathrm{r}=-0,400$ при $\mathrm{p} \leq 0,001$ по Спирмену). В российской выборке выявлен значимый уровень корреляции ( $\leq 0,005$ по Спирмену) для шкалы «Досуг» Bayley-III» и индикаторов «Фокус внимания предмет» $(\mathrm{r}=-0,337)$ и «Эмоциональные переживания к предмету» $(r=-0,361)$.

Становление личностной автономии в раннем возрасте будет являться фундаментом для формирования готовности к самостоятельной жизни в подростковом возрасте [9].

Предполагается дальнейшая работа над клиническими видеонаблюдениями и экспериментальными пробами по стандартизации шкалы оценки личностной автономии ребенка, расширение выборки с ее дифференциацией не только по полу, но и по социально-демографическим и кросс-культурным признакам с включением во взаимодействие значимого взрослого.

\section{Лuтература}

1. Открытая профессиональная экспертиза методики детско-родительского взаимодействия: векторы развития психологического инструментария / И. Н. Галасюк, Т. В. Шинина, Н. Р. Ирганшев [и др.] // Актуальные проблемы психологического знания. Теоретические и практические проблемы психологии. 2018. № 3(48). С. 5-24. Текст: непосредственный.

2. Галасюк И. Н. Семейная психология: методика «Оценка детско-родительского взаимодействия». Evaluation of child-parent interaction (есрі-2.0): практическое пособие / под редакцией И. Н. Галасюк, Т. В. Шинина. Москва: Юрайт, 2019. 223 с. Текст: непосредственный.

3. Галасюк И. Н., Шинина Т. В. Оценка детско-родительского взаимодействия. Evaluationofchild-parentinteraction (ECPI). Москва: Перспектива, 2017. 304 с. Текст: непосредственный.

4. Взаимодействие значимого взрослого с ребенком раннего возраста в России и Вьетнаме / И. Н. Галасюк, Т. В. Шинина, А. А. Шведовская [и др.] // Психологическая наука и образование. 2019. Т. 24, № 6. С. 47-62. Текст: непосредственный.

5. Детско-родительское взаимодействие и развитие ребенка раннего возраста: коллективная монография / Л. В. Токарская, М. А. Лаврова, Н. И. Бакушкина [и др.]; под редакцией Л. В. Токарской; Уральский федеральный университет имени первого Президента России Б. Н. Ельцина. Екатеринбург: Издательство УМЦ УПИ, 2019. 206 с. Текст: непосредственный.

6. Леонтьев Д. А. Саморегуляция, ресурсы и личностный потенциал // Сибирский психологический журнал. 2016. № 62. С. 18-37. Текст: непосредственный.

7. Поливанова К. Н. Детство в меняющемся мире // Современная зарубежная психология. 2016. Т. 5, № 2. С. 5-10. Текст: непосредственный.

8. A Norwegian prospective study of preterm mother-infant interactions at 6 and 18 months and the impact of maternal mental health problems, pregnancy and birth complications / A. R. Misund, S. Braten, P. Nerdrumat [at al.] // BMJ Open. 2015. Vol. 6. P. 1-13.

9. Developmental Origins of Infant Emotion Regulation: Mediation by Temperamental Negativity and Moderation by Maternal Sensitivity / J. C. Thomas, N. Letourneau, T. S. Campbell [at al.] // Developmental Psychology. 2017. Vol. 53, no 4. P. 611-628.

10. Randomised trial of a parent-mediated intervention for infants at high risk for autism: longitudinal outcomes to age 3 years / J. Green, A. Pickles, G. Pasco [at al.] // Journal of Child Psychology and Psychiatry. 2017. Vol. 58, no. 12. P. 1-11. 
11. Shinina T. V., Mitina O. V. Design and Validation of the «Adolescents' Readiness for Independent Living» Questionnaire: Assessment and Development of Life Skills. Psikhologicheskaya nauka i obrazovanie [Psychological Science and Education]. 2019. Vol. 24, no. 1. P. 50-68.

Статья поступила в редакиию 05.06.2021; одобрена после рецензирования 05.07.2021; принята к публикации 29.11.2021.

\section{PERSONAL AUTONOMY OF TODDLERS \\ IN RUSSIAN AND VIETNAM CULTURE}

\section{Tatyana V. Shinina}

Cand. Sci. (Psychology), A/Prof.,

Moscow State University of Psychology and Education

29 Sretenka St., Moscow 127051, Russia

shininatv78@gmail.com

Inna G. Morozova

Senior Lecturer,

Russian State Social University

4/1 Wilhelm Pieck St., Moscow 129226, Russia

inna.opinion@gmail.com

Abstract. The article presents the materials of the study carried out on a sample of dyads of parents and toddlers. The study involved 50 dyads from Russia (Moscow, Ekaterinburg) and Vietnam (NhaTrang) with children aged from 10 to 12 months (M=10.04; SD=0.45), 65\% of which were female. All respondents from Vietnam communicated with children in Vietnamese with further transcription and translation of the text into Russian. The sample is balanced by the socio-economic status of the family, age, and gender. The scale of «Communicative Signals of the Child» was used to evaluate video observations, and the Bayley-III Development Scale - for studying the social and emotional development of the child. The observations were encoded using the software «The Observer XT-15», mathematical data processing was carried out by applying of SPSS 26.0 statistical package. The study has revealed that the development of personal autonomy in Russian and Vietnamese culture is associated with a high level of exploratory activity of the child in the process of interaction with parents, giving him/her the opportunity to show interest in objects and toys. Thus, the level of the indicator «Sensitivity to the Adult» has an inverse correlation with the indicator «Interest to the Object» $(r=-0.444$ at $\mathrm{p} \leq 0.001$ by Spearman) and «Object-Oriented Activity ( $r=-0.400$ at $\mathrm{p} \leq 0.001$ by Spearman).

Keywords: observation method, toddler age, personal autonomy, video analysis, "The Observer-XT”, coding schemes.

Acknowledgments. The work was supported by the Russian Foundation for Basic Research (RFBR) within the framework of the scientific project No. 19-513-92001 "Cross-Cultural Peculiarities of Caregiver-Child Interaction in Russia and Vietnam".

For citation

Shinina T. V., Morozova I. G. Personal Autonomy of Toddlers in Russian and Vietnam Culture. Education. Person. Society. 2021; 2: 76-80 (In Russ.).

The article was submitted 05.06.2021; approved after reviewing 05.07.2021; accepted for publication 29.11.2021. 